\title{
Synthesis of Amino Acid Based Matrix Forms using a Maleic Anhydride with Vinyl Acetate Copolymer
}

\author{
Tatyana V Kryuk and Tatyana G Tyurina* \\ L M Litvinenko Institute of Physical Organic and Coal Chemistry, Donetsk \\ Corresponding author: Tatyana G. Tyurina, L. M. Litvinenko Institute of Physical Organic and Coal Chemistry, Donetsk
}

ARTICLE INFO

Received: 幽 October 14, 2020

Published: 慧 October 23, 2020

Citation: Tatyana V Kryuk, Tatyana G Tyurina. Synthesis of Amino Acid Based Matrix Forms using a Maleic Anhydride with Vinyl Acetate Copolymer. Biomed J Sci \& Tech Res 31(3)-2020. BJSTR. MS.ID.005096.

Keywords: Copolymer; Maleic anhydride; Vinyl acetate; Amino acids; Succinic anhydride; Amidation; Mechanical Activation

\section{ABSTRACT}

Macromolecular amides were synthesized from copolymer of maleic anhydride with vinyl acetate and amino acids: glycine, leucine, isoleucine and lysine. As shown by NMR spectroscopy and pH-metry methods, amidation of the copolymers in a dioxane solution and mechanical activation results in the formation of semi-amide and cyclic imide units. The reaction conditions in a dioxane solution (synthesis time, the presence of a catalyst, the method of introducing amino acid) have insignificant effect on the ratio of the reaction products. During mechanical reaction, an increase in the energy intensity of the grinder facilitates the formation of maleimide units and a significant reduction of the amidation time. In the reaction of copolymers with amino acids in a homogeneous aqueous medium only maleimide cyclic imide units are formed.

Abbreviations: AA: Amino Acid; CI: Cyclic Imide Groups; DMF: Dimethylformamide; DO: 1,4-Dioxane; Gly: Glycine; Ile: Isoleucine; IPA: Isopropyl Alcohol; MA: Maleic Anhydride; Leu: leucine; Lys: Lysine; SA: Semi-Amide Groups; SAn: Succinic Anhydride; TEA: Triethylamine; VA: Vinyl Acetate

\section{Introduction}

An important direction in the development of modern medicine is targeted drug delivery. Biomedical engineering in this field is rapidly expanding due to the development and synthesis of new multifunctional polymer materials that can be created on the basis of $\alpha$-amino acids (AA) [1]. Given the complexity of achieving a clear structure and monodispersity of synthetic biomaterials, extensive preparation procedures that should be performed to achieve a high degree of purity, an alternative to them are polymers which contain amino acids in the side chain. Such materials can be obtained by conjugation or modification of polymers with amino acids, however, to date, a limited number of $\alpha$-amino acid-polymer conjugates are proposed for biomedical use. These include, for example, sustained-release pharmaceutical anxiolytic compositions based on glycine with polylactides, polybutylcyanocrylate [2], poly(Nvinylpyrrolidone) and cellulose derivatives [3]; anabolics based on leucine and isoleucine with polylactide or polybutyl cyanoacrylate $[4,5]$; immunostimulating gel based on lysine and highly active hydrogenated lecithins [6]. This study deals with the influence exerted on the composition of the amidation products by the conditions of the modification of physiologically active maleic anhydride (MA) with vinyl acetate (VA) copolymer [7,8] with simplest amino acid glycine (Gly), branched-chain amino acids leucine (Leu), isoleucine (Ile) and lysine, amino acid with two amino groups (Lys).

\section{Materials and Methods}

Monomers, initiator and solvents were purified by known methods $[9,10]$ (up to $99.98 \%$ of the basic substance). The copolymerization of MA with VA, isolation and purification of the copolymer was carried out according to [11]. Amino acids (manufactured by Snanghai Synnad Fine Chemical Co) were used without further purification. The modification in 1,4-dioxane (DO) or water was performed at an equimolar ratio of MA units and AA without catalyst and in the presence of triethylamine (TEA). A copolymer $(0.185 \mathrm{~g}$ ) was dissolved in $5 \mathrm{ml}$ of solvent, AA was added to the solution (once before heating, or 4 times in equal proportions every $0.5 \mathrm{~h}$ ), TEA was added to the reaction mixture as solution in DO $\left(1.26 \cdot 10^{-6} \mathrm{~mol} / \mathrm{L}\right)$ and the mixture was refluxed for 2 or $4 \mathrm{~h}$ at 
$105^{\circ} \mathrm{C}$. If the synthesis was carried out in dioxane, the solution of the modified polymer after cooling was decanted from unreacted AA and the polymer was precipitated with petroleum ether. After modification in homogeneous aqueous solution the polymer was precipitated with an excess of cold ethyl alcohol or diethyl ether and incubated for $1 \mathrm{~h}$ at $-4{ }^{\circ} \mathrm{C}$.

The final precipitate, MA-VA/AA, was then collected by centrifugation at $3000 \mathrm{rpm}$ for $15 \mathrm{~min}$ [12]. After removal of the liquid phase, the precipitate was dried/purified in a vacuum incubator at $50{ }^{\circ} \mathrm{C}$ for $24 \mathrm{~h}$. The modification products were yellow-brown powders. The mechanical treatment of equimolar mixtures of AA with copolymer or with succinic anhydride (SAn) was performed in an MLW-KM1 laboratory ball mill (applied load 20-30 N) and in a 75T-DrM laboratory vibration grinder (acting load 339-550 N). The content of carboxyl groups ( $\omega(\mathrm{COOH})$, wt \%) in the copolymer samples, its modification products, and amino acids was determined by alkalimetric potentiometric titration; in an aqueous medium and a mixed solvent DMFA-water, used as an titrant aqueous $0.1 \mathrm{M} \mathrm{NaOH}$ and $\mathrm{KOH}$ in IPA respectively. The volume corresponding to the equivalence point was found from the intersection of the second derivative curve $\left(\mathrm{d}^{2} \mathrm{pH} / \mathrm{dV}^{2}\right)$ with the abscissa. The NMR spectra of copolymer and its modification products were recorded with a Bruker Avance II device (400 or 100 $\mathrm{MHz}$ when recording ${ }^{1} \mathrm{H}$ or ${ }^{13} \mathrm{C}$ NMR spectra) at $25{ }^{\circ} \mathrm{C}$ using DMSO- $\mathrm{d}_{6}$ or $\mathrm{D}_{2} \mathrm{O}$ as a solvent

\section{Results and Discussion}

A comparison of the ${ }^{1} \mathrm{H}$ NMR spectrum of the copolymer isolated after $2 \mathrm{~h}$ of reaction with leucine with the initial one (Figures $1 \mathrm{a} \& 1 \mathrm{~b}$, respectively) showed that on Figure 1a signals of protons belonging to both the polymer and amino acid fragments are observed. The protons of the initial copolymer in the spectrum correspond to broadened signals in the region of 2.8-4.6 ppm ( $\mathrm{CH}$ of the MA unit); 2.1-2.8 and 4.8-5.6 ppm ( $\mathrm{CH}_{2}$ and $\mathrm{CH}$ of VA units), which belong to the main polymer chain, and an intense signal in the region of 1.6$2.1 \mathrm{ppm}$. with a maximum at $1.9 \mathrm{ppm}\left(\mathrm{CH}_{3}\right.$ in the side chain of the VA unit) $[9,13]$. Leu fragments correspond to signals: triplet 1 in the region of $0.6-1.0 \mathrm{ppm}$ centered at $0.92 \mathrm{ppm}\left(\mathrm{CH}_{3}\right)$; multiplet 2 in the region of 1.5-1.8 ppm centered at $1.68 \mathrm{ppm}\left(\beta-\mathrm{CH}_{2}, \gamma-\mathrm{CH}\right)$; triplet 3 in the region of 3.6-3.8 ppm centered at $3.71 \mathrm{ppm}(\beta-\mathrm{CH})$ [14]. Evidence that the amino acid enters the side chain of the polymer is a broader view of the signals related to above protons (Figure 1).

At the same time, the broadened waveform does not allow one to evaluate whether signals 1-3 in the ${ }^{1} \mathrm{H}$ NMR spectrum (Figure 1a) belong to units with semi-amide (SA) or cyclic imide groups (CI), which can be formed upon the interaction of amino acids amino groups with carboxyl groups copolymer, as shown on the Scheme $\left(\mathrm{R}=\mathrm{CH}_{2} ; \mathrm{CH}-\mathrm{CH}_{2}-\mathrm{CH}\left(\mathrm{CH}_{3}\right)_{2} ; \mathrm{CH}-\mathrm{CH}\left(\mathrm{CH}_{3}\right)-\mathrm{C}_{2} \mathrm{H}_{5} ; \mathrm{CH}\left(\mathrm{CH}_{2}\right)_{4}-\mathrm{NH}_{2}\right)$ :
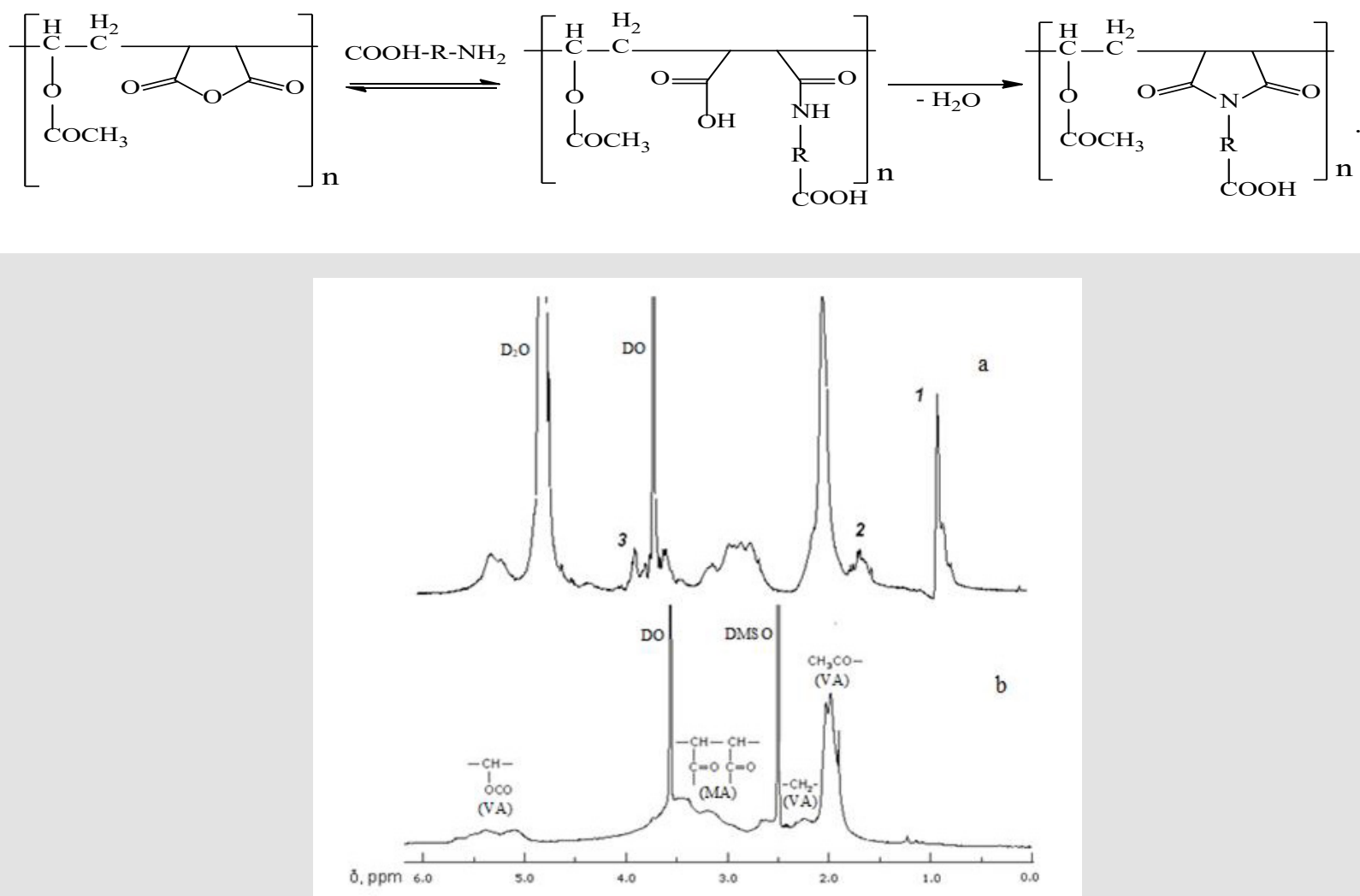

Figure 1: ${ }^{1} \mathrm{H}$ NMR spectra of the MA-VA copolymer (b) and its modification product $\left(105^{\circ} \mathrm{C}, 2 \mathrm{~h}\right)$ with leucine (a). Solvent: $\mathrm{D}_{2} \mathrm{O}(\mathrm{a}), \mathrm{DMSO}_{-} \mathrm{d}_{6}(\mathrm{~b}) ; 400 \mathrm{MHz}, 25^{\circ} \mathrm{C}$. 
The titration curves of the modification products unambiguously confirm the binding of the carboxyl groups of the polymer chain to the amino group of the added AA, since they have one inflection corresponding to a lower alkali volume compared to the titration curves of the initial hydrolyzed copolymer. The presence of one inflection is due to the insufficiently large difference in the dissociation constants of two carboxyl groups in the SA unit ( $\mathrm{p} K_{1}$ of succinic acid 4.21 [15], $\mathrm{p} K_{1}$ of glycine, leucine, isoleucine, lysine 2.18-2.32 [16]), therefore both the groups are titrated together, in contrast to the hydrolyzed MA-VA copolymer, for which the $\mathrm{p} K$ of neighboring carboxyl groups in the structural unit differ by almost 4 orders (4.90 and 8.44 - our data; 4.85 and 8.70 [17]). To enhance their acidic properties, titration in a protophilic polar organic solvent with pronounced differentiating properties, such as DMF, is necessary.

In such an medium one maximum is observed on the isoleucine differential titration curve (Figure 2, curves 1), two maximums on titration curve of the MA-VA copolymer (Figure 2, curves 2) and its modification product (Figure 2, curves 4), due to separate titration of the acid group of the MA unit and the bound amino acid. When titrating a mixture of the copolymer with Ile, three extrema are observed (Figure 2, curve 3) due to one carboxyl group of isoleucine and two $\mathrm{COOH}$ groups of the MA unit. For the MA-VA copolymer amidation product with isoleucine in the DO solution (Figure 2, curve 4), the content of acid groups corresponding to each of the two observed maxima was calculated. The obtained values are 10 $20 \%$ less than the number of carboxyl groups in the copolymer, in which $100 \%$ of the anhydride units transformed into semi-amide units (26.8 wt \%). This suggests that the first inflection on the potentiometric titration curve of amidated copolymers (Figure 2, curve 4) is associated with the neutralization of AA $\mathrm{COOH}$ group, the second one with $\mathrm{COOH}$ of MA group in the semi-amide unit and the modification proceeds with the formation in polymer chains, along with SA units, also a certain number of units with imide groups (Figure 2).
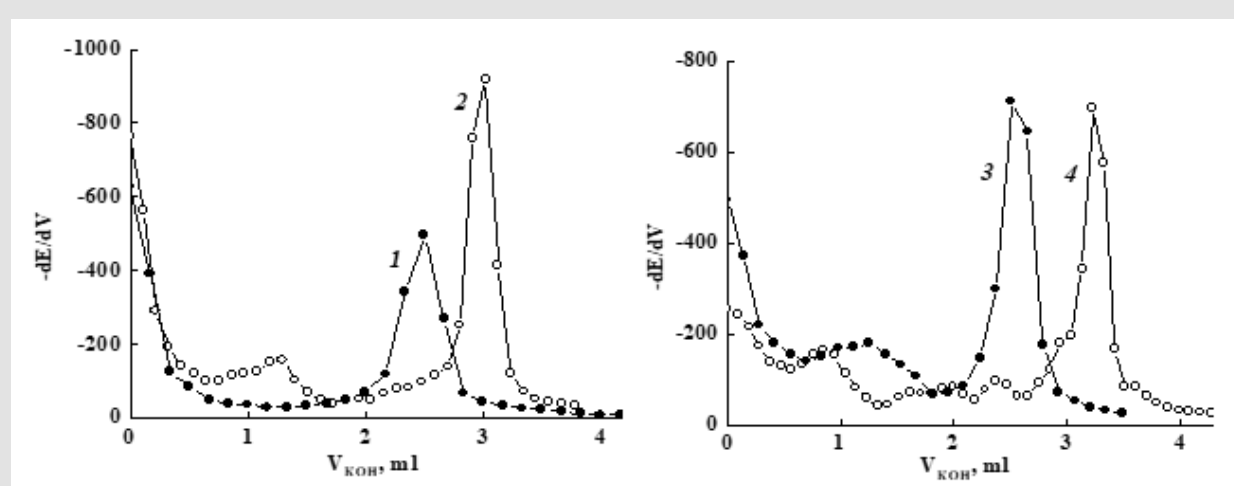

Figure 2:

(1) $1^{\text {st }}$-order differential curves of potentiometric titration of isoleucine,

(2) MA-VA copolymer,

(3) A mixture of the copolymer with Ile and

(4) The modification product of the copolymer with isoleucine $\left(105^{\circ} \mathrm{C}, 2 \mathrm{~h}\right.$ in DO) (4). Solvent: DMF-water mixture.

When the amidation product contains SA and CI units, the total content of $\mathrm{COOH}$ groups determined by titration includes 2 groups in the semi-amide unit (with fraction $x$ ) and 1 group in the maleimide unit [with fraction $(1-x)$ ]. Hence the molecular mass of the copolymer unit:

$\mathrm{M}=x \cdot \mathrm{M}_{\mathrm{uSA}}+(1-x) \cdot \mathrm{M}_{\mathrm{uCI}}=\frac{[2 x \cdot 45+(1-x) \cdot 45] \cdot n_{\mathrm{MA}} / 50}{\omega(\mathrm{COOH})} \cdot 100 \%=\frac{90(1+x) \cdot n_{\mathrm{MA}}}{\omega(\mathrm{COOH})},(1)$

where 45 is the molecular mass of the $\mathrm{COOH}$ group, $\mathrm{g} / \mathrm{mol} ; 2$ - the number of $\mathrm{COOH}$ groups in the initial hydrolyzed copolymer; $n_{M A}$ is the content of MA units in the initial copolymer, wt \%; $\mathrm{M}_{\mathrm{uSA}}$ and $\mathrm{M}_{\mathrm{uCI}}$ - molecular mass of a copolymer unit modified to SA and $\mathrm{CI}$, respectively.

Transforming Equation (1), we obtain an expression for calculating the fraction of semi-amide units:

$$
x=\frac{\mathrm{M}_{\mathrm{uCI}} \cdot \omega(\mathrm{COOH})-90 \cdot n_{\mathrm{MA}}}{90 \cdot n_{\mathrm{MA}}-\omega(\mathrm{COOH}) \cdot\left(\mathrm{M}_{\mathrm{uSA}}-\mathrm{M}_{\mathrm{uCI}}\right)} \cdot(2)
$$

The calculation of the content of $\mathrm{COOH}$ groups for a large number of copolymers samples modified with amino acids under various conditions (Table 1) confirms the assumption that, upon the amidation of MA-VA in a DO solution, the reaction proceeds to the formation of SA and CI units (Table 1). According to the calculation results by Equation (2), the copolymer is most deeply amidated in DO medium when glycine is used. When modified with branchedchain amino acids, a change in the synthesis conditions has little effect on the degree of amidation: in all cases, the content of SA units in the copolymers was 70-80\%; and maleimide ones - 30-20 $\%$, possibly due to poor dissolution of amino acids in the organic solvent and microheterogeneity of the reaction medium, as well as 
the establishment of equilibrium [18]. The use of water as a solvent ensures a homogeneous medium; in this case, only maleimide units are formed. However, in this case it was not possible to achieve complete isolation of the products from the solution.

Table 1: Content of carboxyl, semi-amide and imide groups in products of copolymer modification with amino acids in a dioxane solution.

\begin{tabular}{|c|c|c|c|c|c|c|}
\hline \multicolumn{2}{|c|}{ Copolymer Characteristics } & \multirow{2}{*}{ Amino acid } & \multirow{2}{*}{$\begin{array}{l}\text { Reaction } \\
\text { Conditions }\end{array}$} & \multirow{2}{*}{$\begin{array}{c}\omega(\mathrm{COOH}), \mathrm{wt}^{\mathrm{T}} \% \\
\left(\text { calculation }{ }^{1}\right) / \\
\text { experiment) }\end{array}$} & \multirow{2}{*}{$\begin{array}{l}\text { SA, } \\
\text { mol \% }\end{array}$} & \multirow{2}{*}{$\begin{array}{c}\text { CI, } \\
\text { mol \% }\end{array}$} \\
\hline Mn, Da & $\omega(\mathrm{COOH}), \mathrm{wt} \%$ & & & & & \\
\hline \multirow{10}{*}{26700} & \multirow{10}{*}{47.9} & \multirow{2}{*}{ Gly } & $2 \mathrm{~h}$ & $32.1 / 27.2$ & 54 & 46 \\
\hline & & & $2 \mathrm{~h}$, TEA $^{2}$ ) & $32.1 / 26.6$ & 51 & 49 \\
\hline & & \multirow{5}{*}{ Leu } & $2 \mathrm{~h}$ & $26.8 / 26.6$ & 88 & 12 \\
\hline & & & $\begin{array}{c}2 \mathrm{~h} \text {, proportions } \\
\text { introduction of } \\
\left.\mathrm{AA}^{3}\right)\end{array}$ & $26.8 / 24.6$ & 67 & 33 \\
\hline & & & $2 \mathrm{~h}, \mathrm{TEA}$ & $26,8 / 25,5$ & 77 & 23 \\
\hline & & & $4 \mathrm{~h}$ & $26.8 / 24.6$ & 70 & 30 \\
\hline & & & $4 \mathrm{~h}$, TEA & $26.8 / 25.9$ & 80 & 20 \\
\hline & & \multirow{3}{*}{ Ile } & $2 \mathrm{~h}$ & $26.8 / 24.7$ & 71 & 29 \\
\hline & & & $\begin{array}{l}2 \mathrm{~h} \text {, proportions } \\
\text { introduction of } \mathrm{AA}\end{array}$ & $26.8 / 25.6$ & 78 & 22 \\
\hline & & & $2 \mathrm{~h}$, TEA & $26.8 / 26.4$ & 84 & 16 \\
\hline \multirow{4}{*}{99000} & \multirow{4}{*}{52.8} & \multirow{3}{*}{ Leu } & $2 \mathrm{~h}$ & $28.5 / 24.5$ & 60 & 40 \\
\hline & & & $\begin{array}{l}2 \mathrm{~h} \text {, proportions } \\
\text { introduction of AA }\end{array}$ & $28.5 / 26.0$ & 71 & 29 \\
\hline & & & $4 \mathrm{~h}$ & $28.5 / 20.7$ & 41 & 59 \\
\hline & & Ile & $4 \mathrm{~h}$ & $28.5 / 25.7$ & 69 & 31 \\
\hline
\end{tabular}

1)The content of carboxy groups in the initial copolymer was calculated for the 50:50 mol \% composition, and that in the modified copolymers, for the $100 \%$ conversion of anhydride units to semi-amide ones.

2)The ratio of the unit of MA:TEA $=1: 0.6 \mathrm{~mol} / \mathrm{mol}$.

3)AA was introduced into the reaction system in equal proportions after $0.5 \mathrm{~h}$.

When using ethyl alcohol as a precipitant, as suggested in [12], the maximum yield of conjugates was $21 \%$, and when precipitated in diethyl ether, it was $50 \%$. However, in the latter case, the modification product contains substantial amount of water, the conjugate is a sticky mass, which makes it very difficult to work with. In order to increase the yield of the modified copolymer, to eliminate the stages of its isolation, purification and drying, the possibility of VA-MA copolymer amidation by amino acids by the mechanochemical method was studied. This method is widely used in pharmaceutical practice, in particular, to modify the properties of pharmaceutical substances and obtain dosage forms with improved therapeutic properties [19]. Initially, in the mechanochemical reactor, an interaction was carried out between succinic anhydride as a low molecular weight model of the MA unit in the copolymer and leucine. It was found that the degree of conversion of SAn to semi-amide during the reaction in a ball mill after $1 \mathrm{~h}$ exceeds $80 \mathrm{wt}$ $\%$, the maximum value ( $92 \mathrm{wt} \%$ ) is reached after $2 \mathrm{~h}$ of mechanical activation. In this case a cyclic imide is also formed, its amount increases from 9 to $20 \mathrm{wt} \%$ with an (increase in the of the reagents treatment duration from 1 to $6 \mathrm{~h}$ ).

Modification of SAn by leucine in a vibration grinder under the action of a load by $\sim 20$ times larger than in a ball mill proceeds similarly: the main reaction product is succinic acid semi-amide, but only $1 \mathrm{~min}$ of the reagent's mixture exposure in the vibration grinder is enough for the formation of $86 \mathrm{wt} \% \mathrm{SA}$. The results of potentiometric titration, namely, the presence of succinic semiamide, initial glycine and succinic anhydride in the mechanical activation products was confirmed by the ${ }^{13} \mathrm{C}$ NMR spectrum of the product (Figure 3). The residue of succinic acid $\mathrm{CH}_{2} \mathrm{CH}_{2}$ - in the semiamide (fragment 2 in Figure 4 ) corresponds to signals $2^{\mathrm{IV}}, 2^{\mathrm{V}}$ at 28.3 and 29.1 ppm; group -CO-NH- (fragment 3 in Figure 4) - signal $2^{\text {II }}$ at $173.4 \mathrm{ppm} ; \mathrm{CH}_{2}$ - glycine (fragment 4 in Figure 4 ) - signal $2^{\mathrm{III}}$ at $40.7 \mathrm{ppm}$. The acid groups of the residues of succinic acid and AA in the semi-amide (fragments 1 and 5 in Figure 4) belong to signals 2 and $2^{1}$ at 176.3 and 174.5 ppm. Signals $1,1^{1}$ at 176.5, $28.1 \mathrm{ppm}$ and $3,3^{1}$ at $171.2,40.3 \mathrm{ppm}$ belong to unreacted succinic anhydride $\left(-\mathrm{C}(\mathrm{O}) \mathrm{OC}(\mathrm{O})-,-\mathrm{CH}_{2}-\mathrm{CH}_{2}-\right)$ and glycine $\left(-\mathrm{COOH},-\mathrm{CH}_{2}\right)$ (Figures 3 \& 4). 


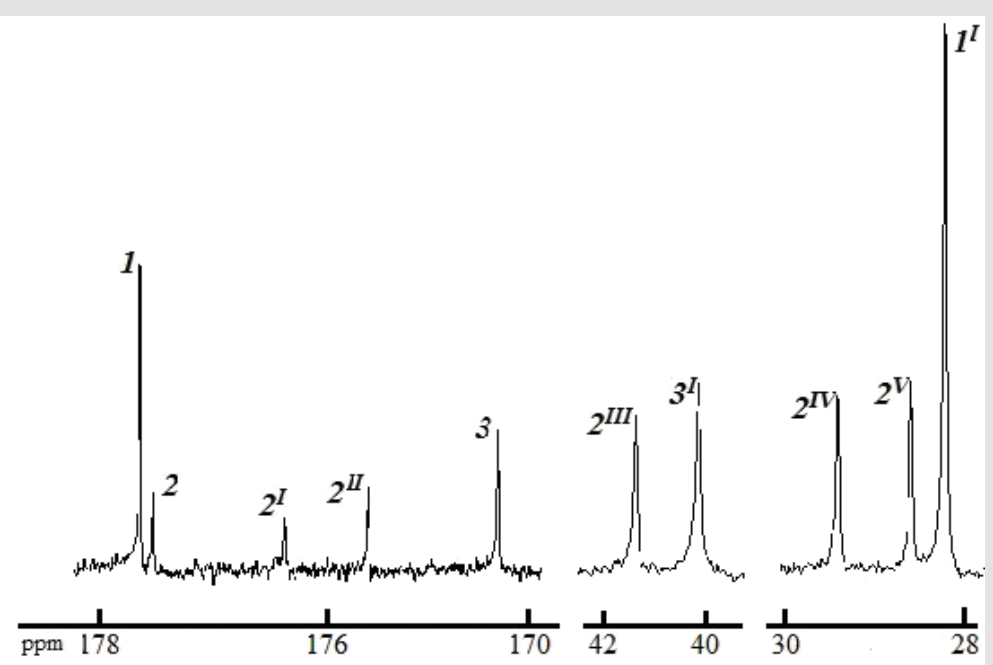

Figure 3: ${ }^{13} \mathrm{C}$ NMR spectrum fragments $\left(400 \mathrm{MHz}, \mathrm{D}_{2} \mathrm{O}\right)$ of the product of succinic anhydride with glycine amidation reaction in a vibratory grinder (2min). Signals 1, 2, 3 belong to the groups of SAn, SA and AA respectively.

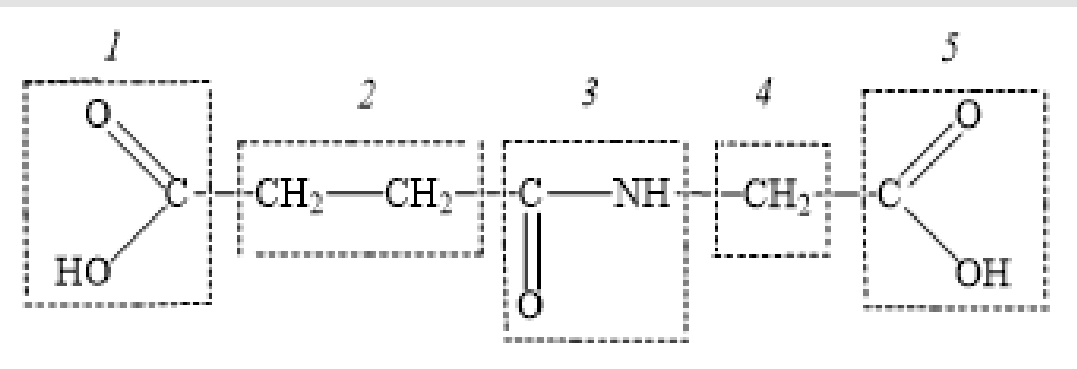

Figure 4: The structure of succinimide.

The results obtained during the mechanical activation of succinic anhydride and AA were taken into account as the basic conditions for the mechanochemical reaction between amino acids and MA-VA copolymer. During the treatment of the copolymer and leucine in a ball mill for $4 \mathrm{~h}$ it was found that the degree of the mixture conversion extremely depends on the magnitude of the applied load. This may be due to a decrease in the specific surface area of the particles and, correspondingly, in the amount of reaction sites, and also to a decrease in the rate of the anhydride diffusion through the amine layer with an additional increase in the pressure [20,21]. Subsequently, the mechanochemical reaction between the copolymer and amino acids in a ball mill was carried out at a load of $20 \mathrm{~N}$, which corresponded to the formation of the maximum amount of semi-amide units. The results of determining of the carboxyl groups content and calculating of the amidated copolymers composition are given in Table 2 . As we can see, the content of carboxyl groups in the composition of the copolymer AA mixture after mechanical activation decreases compared to their amount in the initial sample, which indicates the occurrence of an amidation reaction (Table 2).

Table 2: Data on the composition of products formed by mechanochemical treatment of copolymer with amino acids mixtures (1: 1 $\mathrm{mol} / \mathrm{mol}$ ) according to the titration results in a DMF-water solvent.

\begin{tabular}{|c|c|c|c|c|c|}
\hline Amino Acid & \multicolumn{2}{|c|}{$\begin{array}{l}\text { Reaction Conditions } \\
\text { (Load, Time) }\end{array}$} & $\begin{array}{c}\omega(\mathrm{COOH}), \mathrm{wt} \% \text { (Calculation } 1) / \\
\text { Experiment) }\end{array}$ & $\begin{array}{l}\text { SA, } \\
\text { wt } \%\end{array}$ & $\begin{array}{l}\text { Initial Mixture, } \\
\text { wt \% }\end{array}$ \\
\hline \multirow{2}{*}{ Leu } & $20 \mathrm{~N}$ & $4 \mathrm{~h}$ & $42.8 / 41.9$ & 6 & 94 \\
\hline & $339-550 \mathrm{~N}$ & $5 \mathrm{~min}$ & $42.8 / 34.0$ & 62 & 38 \\
\hline Ile & $20 \mathrm{~N}$ & $6 \mathrm{~h}$ & $42.8 / 29.6$ & 93 & 7 \\
\hline \multirow{3}{*}{ Lys } & \multirow{3}{*}{$339-550 \mathrm{~N}$} & $1 \mathrm{~min}$ & 38.6 / 38.5 & 1 & 99 \\
\hline & & $2 \min$ & $38.6 / 24.7$ & 92 & $82)$ \\
\hline & & $3 \mathrm{~min}$ & 38.6 / 28.5 & 79 & 21 \\
\hline
\end{tabular}

1) $\omega(\mathrm{COOH})$ was calculated for the mixture composition (MA unit in MA-VA):AA = 50:50 mol\%.

2)CI, mass fraction. 
When leucine is used at low load (20 N), the amidation of MA units proceeds to a small extent, the increase in load significantly changes the process: after $5 \mathrm{~min}$ of the reaction the amount of semi-amide units is $62 \mathrm{wt} \%$. In the case of isoleucine an almost complete modification of MA units to semi-amide takes place even during mechanical activation in a ball mill. The reaction between the copolymer and lysine in the vibrator apparatus leads to a deeper amidation: after 2 min of co-grinding maleimide units also form along with the semi-amide ones (the ratio of SA:CI is $~ 9: 1$ ). Longer treatment, as in the case of amidation of succinic anhydride, reduces the effectiveness of the modification. Thus, when the MAVA copolymer is modified with $\alpha$-amino acids under the conditions of the mechanochemical reaction, the polymer units are converted into semi-amide units, although synthesis in solution can be more efficient, which depends on the nature of AA. If the applied load is large, there is a maximum on the dependence of the modification degree on the treatment time. To achieve a high degree of anhydride groups and amino acids conversion, it is necessary to control the reaction time and the magnitude of the applied load.

\section{Conclusion}

During the amidation of maleic anhydride with vinyl acetate copolymers by amino acids in a dioxane solution $\left(105^{\circ} \mathrm{C}, 2\right.$ or $4 \mathrm{~h}$, with triethylamine and without a catalyst), copolymers containing units of semi-amide and maleimide were formed. The ratio of units was 1:0.9 when modified with glycine, 1:0.2-0.5 - with leucine, isoleucine. Modification of the copolymer in water with branched chain amino acids leaded to the complete conversion of maleic anhydride units into maleimide ones. During the mechanical treatment of the copolymer with amino acids, their covalent interaction proceeded, the composition of the formed conjugates depended on the time of mechanical activation and the applied load magnitude.

\section{References}

1. Liarou E, Varlas S, Skoulas D, Tsimblouli C, Sereti E, et al. (2018) Smart polymersomes and hydrogels from polypeptide-based polymer systems through $\alpha$-amino acid $\mathrm{N}$-carboxyanhydride ring-opening polymerization. From chemistry to biomedical applications. Progr Polym Sci 83: 28-78.

2. Kuznetsov SL, Ivanov SV, Bubelo VD, Vorontsov EA, Gurov VA, et al. (2012) Glycine-based sustained release pharmaceutical composition and method for its preparation. Pat RU 2457835 C1.

3. Khannanov TSh, Anisimov AN, Kamaeva SS, Kashapova KI, Lefterova MI, et al. (2016) Pharmaceutical composition, containing combination of glycine and tetrametiltetraaza-biciklooktandiona (variants). Pat RU 2576240 .
4. Zavradashvili N, Jokhadze G, Gverdtsiteli M, Tugushi D, Katsarava R (2017) Biodegradable functional polymers composed of naturally occurring amino acids. Res Rev Polym 8(1): 105-128.

5. Wolfe RR, Wei J (2014) Methods for improving muscle and heart function. Pat US 9597367B2.

6. Ivanov VN, Bunimovich MA (2014) Pharmaceutical composition containing lysine and enzymes: lysozyme, deoxyribonuclease and / or peroxidase for external treatment and prevention of infections caused by herpes virus type 1,2 and bacterial complications caused by herpes infection. Pat RU 2535053.

7. Spiridon D, Panaitescu L, Ursu D, Uglea CV, Popa I, et al. (1997) Synthesis and biocompatibility of maleic anhydride copolymers: 1 . maleic anhydride-vinyl acetate, maleic anhydride-methyl methacrylate and maleic anhydride-styrene. Polym Int 43(2): 175-181.

8. Karakuş G, Malatyali E, Zengin HB, Degerli S (2013) In vitro amoebicidal activity of poly(maleic anhydride-co-vinyl acetate) copolymer on Acanthamoeba spp. trophozoites and cysts. Basic Clin Sci 2: 1-14.

9. Chitanu GC, Popescu I, Carpov A (2006) Synthesis and characterization of maleic anhydride copolymers and their derivatives. 2. New data on the copolymerization of maleic anhydride with vinyl acetate. Rev Roum Chim 51(9): 923-929.

10. Guven G, Rzaev ZMO (2008) Complex-radical copolymerization of $\mathrm{N}$-vinylpyrrolidone with isostructural analogs of maleic anhydride. Polym Bul 60: 741-752.

11. Tyurina TG, Kryuk TV (2019) Modification of maleic anhydride copolymers with aliphatic alkylamines and sulfanilamide. Russ J Appl Chem 92(3): 351-359.

12. Karakuş G, Ece A, Yaglioglu AS, Zengin HB, Karahan M (2017) Synthesis, structural characterization, and antiproliferative/cytotoxic effects of a novel modified poly(maleicanhydride-co-vinyl acetate)/doxorubicin conjugate. Polym Bul 74(6): 2159-2184.

13. Nemtoi G, Beldie C, Tircolea C, Popa I, Cretescu I, et al. (2001) Behaviour of the poly(maleic anhydride-co-vinyl acetate) copolymer in aqueous solutions. Eur Polym J 37: 729-735.

14. Tikhonov VP, Kostromina NA (1977) Study of the conformational transformations of leucine, isoleucine and valine by PMR. Theor Exp Chem 13(4): 496-503.

15. Lurie YY (1989) Handbook of Analytical Chemistry. Mir Publishers.

16. Harned HS, Owen BB (1958) The physical chemistry of electrolytic solutions. Reinhold, NYC $3^{\text {rd }}$ (Edi.).

17. Monobe K (1960) Studies on the electrochemical properties of copolymers of maleic acid. I. Potentiometric titration at low ionic strength. Rev Phys Chem Japan 30(2): 145-154.

18. Sadovnikov AI (2007) Regularities of amide formation with participation of carboxylic acids anhydrides and aromatic amines. Rus J Chem Chem Tech 50(5): 3-16.

19. Colombo I, Grassi G, Grassi M (2009) Drug mechanochemical activation. J Pharm Sci 98(11): 3961-3986.

20. Weng HL, Parrott EL (1984) Solid-solid reaction between sulfacetamide and phthalic anhydride. J Pharm Sci 73(8): 1059-1063.

21. Boldyrev VV (2006) Mechanochemistry and mechanical activation of solids. Rus Chem Rev 75(3): 177-189. 
ISSN: 2574-1241

DOI: 10.26717/BJSTR.2020.31.005096

Tatyana G Tyurina. Biomed J Sci \& Tech Res

(C) (P) This work is licensed under Creative

Submission Link: https://biomedres.us/submit-manuscript.php

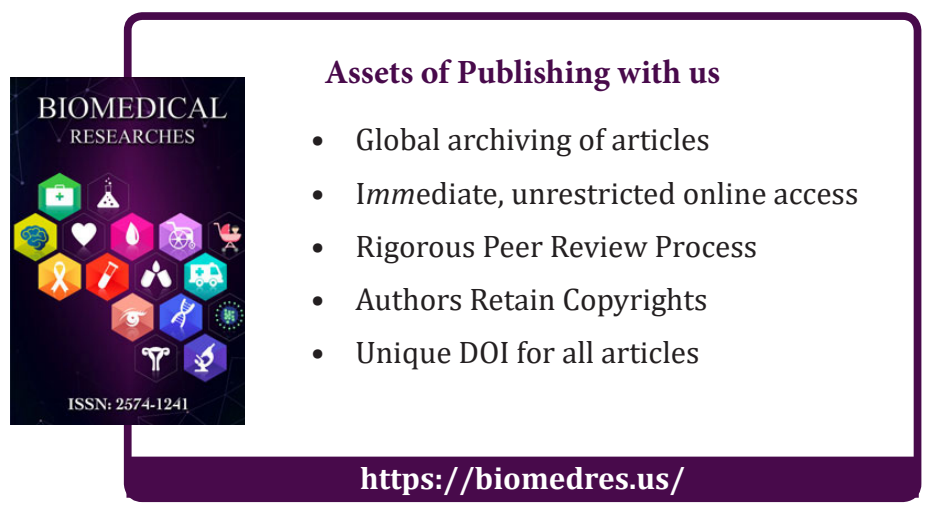

